\title{
Single nucleotide polymorphisms of the very low density lipoprotein receptor (VLDLR) gene
}

Received: April 30, 2001 / Accepted: May 1, 2001

\begin{abstract}
The very low density lipoprotein receptor (VLDLR) has a potentially important role in lipoprotein metabolism and Alzheimer's disease. We developed amplification primers for most of the coding region and $3^{\prime}$ untranslated region of $V L D L R$ and used sequencing of genomic DNA to examine these regions of $V L D L R$ in subjects with familial combined hyperlipidemia and in normal controls. We identified ten novel single nucleotide polymorphisms (SNPs) for VLDLR. We also found one rare coding sequence variant, $\mathrm{S}>\mathrm{R} 153$, in a subject with familial combined hyperlipidemia, which was absent from 2360 normal alleles. The identification of intron-exon boundaries, amplification primers, and SNPs provides tools to investigate $V L D L R$ for genetic association and linkage studies.
\end{abstract}

Key words Lipoproteins · Metabolism · Alzheimer's disease - Atherosclerosis - Genomic DNA - Sequencing · Complex traits

\section{Introduction}

The human very low density lipoprotein receptor (VLDLR; OMIM 192977) appears to play a key role in triglyceride metabolism. The $V L D L R$ gene on 9p24 is highly expressed in heart, muscle, and adipose tissues, which are active in fatty acid metabolism, but is not expressed in liver (Oka et al. 1994). The $V L D L R$ gene contains 19 exons spanning $\sim 40 \mathrm{~kb}$ and its intron-exon organization is almost identical to that of the low density lipoprotein receptor (LDLR; OMIM 143890). In contrast to $L D L R$, however, no human

S.E. Near $\cdot$ J. Wang $\cdot$ R.A. Hegele $(\bowtie)$

Blackburn Cardiovascular Genetics Laboratory, John P. Robarts Research Institute, 406-100 Perth Drive, London, ON N6A 5K8, Canada

Tel. +1-519-663-3461; Fax +1-519-663-3789

e-mail: robert.hegele@rri.on.ca mutations or single nucleotide polymorphisms (SNPs) have yet been reported in $V L D L R$. A polymorphic triplet repeat in $V L D L R$ has been reported to be associated with Alzheimer's disease (Okuizumi et al. 1995). Because of the possible association with Alzheimer's disease and because of its potential role in lipoprotein metabolism, we developed amplification primers to sequence the genomic DNA of most of the coding region and $3^{\prime}$-untranslated region of $V L D L R$ in subjects with familial combined hyperlipidemia and in normal control subjects.

\section{Subjects and methods}

Study subjects

We screened genomic DNA from samples taken from 12 unrelated subjects with familial combined hyperlipoproteinemia (defined as plasma triglyceride and LDL cholesterol concentrations both in excess of the 95th percentile for age and sex, with at least one other affected relative) and 6 unrelated normolipidemic subjects. Samples from a DNA archive of 20 unaffected normal Caucasian subjects were screened to determine allele frequencies. For the 540C $>\mathrm{T}$ SNP, 1180 normolipidemic subjects from six ethnic groups were screened. The study was approved by the Ethics Review Panel, University of Western Ontario.

Screening the $V L D L R$ gene for DNA variants

Insufficient published sequence data were available to develop primers that would span at least $50 \mathrm{bp}$ of DNA within the introns adjacent to the intron-exon boundaries. We used an established method to identify most intron-exon boundaries of $V L D L R$ (Table 1) and at least $100 \mathrm{bp}$ of flanking intron sequence (Wang et al. 2000). We used this information to develop primers to amplify coding regions of $V L D L R$ and intron-exon boundaries from genomic DNA. 
Table 1. Intron-exon boundaries for $V L D L R$ gene

\begin{tabular}{rll}
\hline Exon & $5^{\prime}$ Boundary & $3^{\prime}$ Boundary \\
\hline 2 & & CTGTGgtaagtaaagagtttgatgac \\
3 & ccttcaaataaacgtttgtagTAAAG & GTGCCgtgagtgtaacttgcttggc \\
4 & agacgtgtatatcatcaacagATATG & CTGTGgtaagaagatcagtgttgagt \\
5 & gggcatctctctcttaatagGCAAT & CTGTCgtaagtagctttctagcatgg \\
6 & tggtgtttctcctttgtagCCTCT & AAATGgtaagggtttcttcttgttgg \\
7 & cttcttgttctctttgtagTCAAT & GTGTCgtaagtgtacttgttgttcaa \\
8 & actactacattttattccagATATA & TGGAGgtgagtctaagaagaaaacct \\
9 & taattctgatttcctccagATATT & AGTAGgtaaatgaacttggactggta \\
10 & acccagacttccatcttgcagGCAAA & TTCAGgtaactttcagttccttttgt \\
11 & ttgtgacctattctgtttcagTGCCT & TCTGGgtttgtagtctgttttccatc \\
12 & ttctcatttaatttttcacagCTTTG & ACTTGgtatgtatgttcttccttctc \\
13 & gacaattctttcctacctagACCTT & TTGAGgtaagatgtgtctacatcaaa \\
14 & aattgtgggcttctgtttagGATCG & ATCAGgtaccgtggagaagcacagtc \\
15 & ggtatttttttcctgactagGTAAA & TCAAAgtaaggcattttgtgtttcaa \\
16 & ttcttggttttataattcagGTACT & TGGAGgtattgagttcagtactgcaa \\
17 & attcctttattcctctgtagGGATC & TCTCTgtaagtagatttcctacaagt \\
18 & ctaccctctgattttttcagTGCTC & CAGCAgtaagtcagctttgtgtcttt \\
19 & tatacttcttctttccacagATATC & \\
\hline
\end{tabular}

Table 2. Amplification primers for $V L D L R$ gene

\begin{tabular}{|c|c|c|}
\hline Exon & Primer sequence & Product size (bp) \\
\hline \multirow[t]{2}{*}{3} & Forward: 5'-CTGGATATTGGCAGTTGAGTG & 398 \\
\hline & Reverse: 5'-CCCTTGGAGTCAATTGACCTA & \\
\hline \multirow[t]{2}{*}{4} & Forward: 5'-TGCATTGATCAGTTCTGAGGC & 275 \\
\hline & Reverse: 5'-GTCAATGTCAGTGCGTCTTCA & \\
\hline \multirow[t]{2}{*}{5} & Forward: 5'-GACAAGAATCTTGAACGGAC & 482 \\
\hline & Reverse: 5'-GTTGATACAGGGAAGAGAAC & \\
\hline \multirow[t]{2}{*}{6} & Forward: 5'-GAGGACAACTGTCGTAAGTAG & 364 \\
\hline & Reverse: 5'-CATTCTCCACTTCTGCACTTG & \\
\hline \multirow[t]{2}{*}{7} & Forward: 5'-GATGGTTCCGATGAAGTCAAC & 290 \\
\hline & Reverse: 5'-CTGGATTGTGTCAAACTTCCAG & \\
\hline \multirow[t]{2}{*}{8} & Forward: 5'-GGTCTTAGACAAATCGTGGG & 293 \\
\hline & Reverse: 5'-CTAТССТТТССАТСАССТG & \\
\hline \multirow[t]{2}{*}{9} & Forward: 5'-AGGTATAGGAGCAGCAAGAC & 294 \\
\hline & Reverse: 5'-GAGGTTAGCAGCATTGTTCTC & \\
\hline \multirow[t]{2}{*}{10} & Forward: 5'-TCCAGAACAGATACTACTGAGG & 357 \\
\hline & Reverse: 5'-CCCAAGTGACAATGACTTATGTC & \\
\hline \multirow[t]{2}{*}{11} & Forward: 5'-TAGGATCAGTAAGCAGCATGG & 434 \\
\hline & Reverse: 5'-GACCTACACAGATACCATTCC & \\
\hline \multirow[t]{2}{*}{12} & Forward: 5'-GTCACTAGAGAATGCCTTGAG & 314 \\
\hline & Reverse: 5'-GTCCAGAATTCACCATGGAG & \\
\hline \multirow[t]{2}{*}{13} & Forward: 5'-CAGAGTAGTAGTGGCTTGTC & 300 \\
\hline & Reverse: 5'-TCTCAAGCCATGTTCAGCTGC & \\
\hline \multirow[t]{2}{*}{14} & Forward: 5'-AGACACTAAGTCCCAGAAGC & 407 \\
\hline & Reverse: 5'-CAAAGAGCTACTGACATCCA & \\
\hline \multirow[t]{2}{*}{15} & Forward: 5'-GACTCAGGTCTTCAACATGTAG & 454 \\
\hline & Reverse: 5'-GGTATGTTGACACTTTAGTCTCC & \\
\hline \multirow[t]{2}{*}{16} & Forward: 5'-GTACAACTTAGTTCAGCAGTGG & 280 \\
\hline & Reverse: 5'-CTGTAGATACAAAGAGTGTGGC & \\
\hline \multirow[t]{2}{*}{17} & Forward: 5'-CAGAGTTGTTCCTGGTGTTCA & 354 \\
\hline & Reverse: 5'-AGCGAACGTAATTCAGTGTCA & \\
\hline \multirow[t]{2}{*}{18} & Forward: 5'-GGCTGAACTTGTTTCAAGCTCC & 455 \\
\hline & Reverse: 5'-GTGTTTGGTAACTCCATCATCC & \\
\hline \multirow[t]{2}{*}{19} & Forward: 5'-CTAGAGTTGCCATCAGTGAGTG & 317 \\
\hline & Reverse: 5'-CAGATACTCGGTAACCACATCC & \\
\hline
\end{tabular}

Primer sequences are shown in Table 2. Primers were designed to anneal at a single temperature, which allowed for use of a single amplification apparatus. Amplification conditions were $94^{\circ} \mathrm{C}$ for $5 \mathrm{~min}$, followed by 30 cycles of $30 \mathrm{~s}$ each at $94^{\circ} \mathrm{C}, 58^{\circ} \mathrm{C}$, and $72^{\circ} \mathrm{C}$, and ending with a single 10 -min extension step at $72^{\circ} \mathrm{C}$.

\section{Genotyping of $V L D L R$ SNPs}

Six common $V L D L R$ SNPs and the rare 540C $>$ T SNP were found to alter recognition sites for restriction endonucleases (Table 3), which became the basis for genotyping. The remaining four common VLDLR SNPs did not alter 
Table 3. $V L D L R$ gene SNPs

\begin{tabular}{|c|c|c|c|}
\hline Position & Nucleotide change & Detection method & Frequency \\
\hline Exon $5(\mathrm{~S}>\mathrm{R} 153)$ & $540 \mathrm{C}>\mathrm{T}$ & $B b v \mathrm{I}$ digestion & Absent from 2360 normal alleles \\
\hline-3 nt I8/e 9 boundary & $\mathrm{C}>\mathrm{T}$ & $B f a I$ digestion & T: 0.25 \\
\hline$+27 \mathrm{nt}$ e9/I9 boundary & $\mathrm{G}>\mathrm{A}$ & MunI digestion & A: 0.25 \\
\hline$-17 \mathrm{nt} \mathrm{I} / \mathrm{e} 10$ boundary & $\mathrm{A}>\mathrm{T}$ & DdeI digestion & T: 0.25 \\
\hline Exon $14(\mathrm{Q} 662)$ & $2067 \mathrm{~A}>\mathrm{G}$ & Direct sequencing & 2067G: 0.25 \\
\hline$-75 \mathrm{nt} \mathrm{I} 15 / \mathrm{e} 16$ boundary & $\mathrm{A}>\mathrm{G}$ & NlaIII digestion & G: 0.30 \\
\hline$-67 \mathrm{nt} \mathrm{I15/e16}$ boundary & $\mathrm{T}>\mathrm{C}$ & ScrFI digestion & C: 0.05 \\
\hline$-30 \mathrm{nt}$ I15/e16 boundary & $\mathrm{T}>\mathrm{C}$ & MseI digestion & C: 0.05 \\
\hline$-65 \mathrm{nt}$ I16/e17 boundary & $\mathrm{T}>\mathrm{C}$ & Direct sequencing & C: 0.05 \\
\hline$+8 \mathrm{nt}$ e17/I17 boundary & $\mathrm{G}>\mathrm{T}$ & Direct sequencing & T: 0.35 \\
\hline 3'-UTR & $2801 \mathrm{G}>\mathrm{A}$ & Direct sequencing & A: 0.05 \\
\hline
\end{tabular}

nt, Nucleotide; UTR, untranslated region

restriction endonuclease recognition sites (Table 3) and these were genotyped by using direct genomic DNA sequencing.

The $V L D L R$ SNP that was located 3 nucleotides (nt) upstream of the intron 8/exon 9 boundary was genotyped by amplification of a 154-bp fragment with primers F5'CAGGTGATGGGAAAGGATAGTATGTAC-3' and R5'-ACGACTACATTCACACTTGTAACCGC-3'. The amplification conditions were $94^{\circ} \mathrm{C}$ for $5 \mathrm{~min}$, followed by 30 cycles of 30 s each at $94^{\circ} \mathrm{C}, 55^{\circ} \mathrm{C}$, and $72^{\circ} \mathrm{C}$, and ending with a single 10-min extension step at $72^{\circ} \mathrm{C}$. Digestion of the [-3]C allele with $B f a \mathrm{I}$ produced two fragments of 27 and $127 \mathrm{bp}$, whereas digestion of the $[-3] \mathrm{T}$ allele produced three fragments of 27,42 , and $85 \mathrm{bp}$. These fragments were resolved by electrophoresis in $10 \%$ polyacrylamide gels.

The VLDLR SNP that was located $27 \mathrm{nt}$ downstream from the exon 9/intron 9 boundary was genotyped by amplification of a 147-bp fragment with primers F5'-TGAACTTGGACTGGTATGGCA-3' and R5'GCTATTTGACCTATACTGCTG-3'. The amplification conditions were $94^{\circ} \mathrm{C}$ for $5 \mathrm{~min}$, followed by 30 cycles of 30 s each at $94^{\circ} \mathrm{C}, 53^{\circ} \mathrm{C}$, and $72^{\circ} \mathrm{C}$, and ending with a single 10 -minute extension step at $72^{\circ} \mathrm{C}$. Digestion of the $[+27] \mathrm{G}$ allele with MunI produced a single fragment of $147 \mathrm{bp}$, whereas digestion of the $[+27] \mathrm{A}$ allele produced two fragments of 20 and $127 \mathrm{bp}$. These fragments were resolved after electrophoresis in $10 \%$ polyacrylamide gels.

The VLDLR SNP that was located $17 \mathrm{nt}$ upstream of the intron $9 /$ exon 10 boundary was genotyped by amplification of a 154-bp fragment with primers F5'-GGCAGG AACTCCAGAACAGATACTACTGAGG-3' and R5'CTTGGCTCTTTGCCTGCAAGATGGAACTC- ${ }^{\prime}$. The amplification conditions were $94^{\circ} \mathrm{C}$ for $5 \mathrm{~min}$, followed by 30 cycles of $30 \mathrm{~s}$ each at $94^{\circ} \mathrm{C}, 58^{\circ} \mathrm{C}$, and $72^{\circ} \mathrm{C}$, and ending with a single 10 -minute extension step at $72^{\circ} \mathrm{C}$. Digestion of the [-17]A allele with DdeI produced two fragments of 26 and $128 \mathrm{bp}$, whereas digestion of the [-17]T allele produced three fragments of 26,98 , and $30 \mathrm{bp}$. These fragments were resolved by electrophoresis in $10 \%$ polyacrylamide gels.

The $V L D L R$ SNP that was located $75 \mathrm{nt}$ upstream of the intron 15 /exon 16 boundary was genotyped by amplification of a 280-bp fragment with primers F5'-GTACAACT
TAGTTCAGCAGTGG-3' and R5'-CTGTAGATACAA AGAGTGTGGC-3'. The amplification conditions were $94^{\circ} \mathrm{C}$ for $5 \mathrm{~min}$, followed by 30 cycles of $30 \mathrm{~s}$ each at $94^{\circ} \mathrm{C}$, $58^{\circ} \mathrm{C}$, and $72^{\circ} \mathrm{C}$, and ending with a single 10 -minute extension step at $72^{\circ} \mathrm{C}$. Digesting the $[-75] \mathrm{A}$ allele with NlaIII produced three fragments of 62,28 , and $190 \mathrm{bp}$, whereas digestion of the $[-75] \mathrm{G}$ allele produced two fragments of 90 and $190 \mathrm{bp}$. These fragments were resolved by electrophoresis in $10 \%$ polyacrylamide gels.

The VLDLR SNP that was located $30 \mathrm{nt}$ upstream of the intron 15/exon 16 boundary was genotyped by amplification of a 280-bp fragment with primers F5'-GTACAACTTAGT TCAGCAGTGG-3' and R5'-CTGTAGATACAAAGAG TGTGGC- $3^{\prime}$. The amplification conditions were $94^{\circ} \mathrm{C}$ for $5 \mathrm{~min}$, followed by 30 cycles of $30 \mathrm{~s}$ each at $94^{\circ} \mathrm{C}, 58^{\circ} \mathrm{C}$, and $72^{\circ} \mathrm{C}$, and ending with a single 10 -minute extension step at $72^{\circ} \mathrm{C}$. Digestion of the $[-30] \mathrm{T}$ allele with $\mathrm{Mse}$ I produced four fragments of $42,62,139$, and $37 \mathrm{bp}$, whereas digestion of the $[-30] \mathrm{C}$ allele produced three fragments of 42,201 , and $37 \mathrm{bp}$. These fragments were resolved by electrophoresis in $10 \%$ polyacrylamide gels.

The $V L D L R$ SNP that was located $67 \mathrm{nt}$ upstream of the intron 15/exon 16 boundary was genotyped by amplification of a 280-bp fragment with primers F5'-GTACAACTTAGT TCAGCAGTGG-3' and R5'-CTGTAGATACAAAGAG TGTGGC-3'. The amplification conditions were $94^{\circ} \mathrm{C}$ for $5 \mathrm{~min}$, followed by 30 cycles of $30 \mathrm{~s}$ each at $94^{\circ} \mathrm{C}, 58^{\circ} \mathrm{C}$, and $72^{\circ} \mathrm{C}$, and ending with a single 10 -minute extension step at $72^{\circ} \mathrm{C}$. Digesting the $[-67] \mathrm{T}$ allele with $S c r F I$ produced five fragments of $68,30,11,102$, and $69 \mathrm{bp}$, whereas digestion of the [-67]C allele produced four fragments of $98,11,102$, and $69 \mathrm{bp}$. These fragments were resolved by electrophoresis in $10 \%$ polyacrylamide gels.

The VLDLR 540C $>$ T SNP that resulted in a missense mutation at residue 153 ( $\mathrm{S}>\mathrm{R} 153)$ was genotyped by amplification of a 483-bp fragment with primers F5'GACAAGAATCTTGAACGGAC-3' and R5'-GTTGAT ACAGGGAAGAGAAC-3'. The amplification conditions were $94^{\circ} \mathrm{C}$ for $5 \mathrm{~min}$, followed by 30 cycles of $30 \mathrm{~s}$ each at $94^{\circ} \mathrm{C}, 58^{\circ} \mathrm{C}$, and $72^{\circ} \mathrm{C}$, and ending with a single 10 -minute extension step at $72^{\circ} \mathrm{C}$. Digestion of the [540]C allele with $B b v \mathrm{I}$ produced four fragments of $96,68,62$, and $257 \mathrm{bp}$, whereas digestion of the [540]T allele produced three frag- 
ments of 96,130, and $257 \mathrm{bp}$. These fragments were resolved after electrophoresis in $10 \%$ polyacrylamide gels.

\section{Statistical analysis}

SAS version 6.12 (SAS Institute, Cary, NC, USA) was used for statistical analyses. Allele frequencies were determined from electrophoretogram tracings of genomic DNA sequence, except for two SNPs assayed by using restriction digestion. Chi-square analysis tested the deviation of genotype frequencies from Hardy-Weinberg predictions. The nominal level of significance for statistical analyses was $P<0.05$.

\section{Results}

\section{Identification of SNPs}

Most intron-exon boundaries were identified (Table 1) and amplification primers were developed (Table 2). Sequencing found ten common SNPs in subjects with familial combined hyperlipidemia and in normal controls. In addition, a rare coding SNP (540C $>$ T; S $>$ R153) was found in a subject with familial combined hyperlipidemia.

\section{SNP frequencies}

The observed genotype frequencies of all SNPs did not deviate from the predictions of the Hardy-Weinberg equation. The allele frequencies are shown in Table 3. The $V L D L R$ 540C $>$ T SNP was absent from 2360 alleles taken from normal subjects.

\section{Discussion}

We report intron-exon boundaries and definition of primer sets to amplify the coding sequences of the $V L D L R$ gene and the use of these amplification primers for genomic DNA sequencing, which has resulted in the identification of ten novel SNPs and a rare coding region variant found only in a single subject to date. Because we did not examine the $V L D L R$ promoter regions and exon 1, we cannot absolutely rule out the presence of such SNPs. The reagents described in this report could be helpful to screen the $V L D L R$ gene when it becomes a candidate for phenotypes, either through positional cloning, analogy with other phenotypes, or expression data showing changes in response to particular experimental interventions. The reported $V L D L R$ SNPs could also be helpful in linkage mapping and for association studies.

\section{References}

Oka K, Tzung K-W, Sullivan M, Lindsay E, Baldini A, Chan L (1994) Human very-low-density lipoprotein receptor complementary DNA and deduced amino acid sequence and localization of its gene (VLDLR) to chromosome band 9q24 by fluorescence in situ hybridization. Genomics 20:298-300

Okuizumi K, Onodera O, Namba Y, Ikeda K, Yamamoto T, Seki K, Ueki A, Nanko S, Tanaka H, Takahashi H, Oyanagi K, Mizusawa H, Kanazawa I, Tsuji S (1995) Genetic association of the very low density lipoprotein (VLDL) receptor gene with sporadic Alzheimer's disease. Nat Genet 11:207-209

Wang J, Burnett JR, Near S, Young K, Zinman B, Hanley AJ, Connelly PW, Harris SB, Hegele RA (2000) Common and rare ABCA1 variants affecting plasma HDL cholesterol. Arterioscler Thromb Vasc Biol 20:1983-1989 